\title{
A Novel Class of Norovirus Inhibitors Targeting the Viral Protease with Potent Antiviral Activity In Vitro and In Vivo
}

\author{
Jana Van Dycke ${ }^{1,+} \mathbb{D}$, Wenhao Dai ${ }^{2,+} \mathbb{D}$, Zoe Stylianidou ${ }^{1}$, Jian Li ${ }^{2,3}$, Arno Cuvry ${ }^{1} \mathbb{D}$, Emma Roux $^{1}$, Bingqian Li $^{2}$, \\ Jasper Rymenants ${ }^{1}\left(\mathbb{D}\right.$, Lindsey Bervoets ${ }^{1}$, Peter de Witte ${ }^{4}$, Hong Liu ${ }^{2, *}, \ddagger$, Johan Neyts $1, \ddagger(\mathbb{D}$ \\ and Joana Rocha-Pereira ${ }^{1, * \mathbb{D}}$
}

1 Laboratory of Virology and Chemotherapy, KU Leuven-Department of Microbiology, Immunology and Transplantation, Rega Institute, 3000 Leuven, Belgium; Jana.vandycke@kuleuven.be (J.V.D.); zstylianidou@hotmail.com (Z.S.); Arno.cuvry@kuleuven.be (A.C.); emma.roux@kuleuven.be (E.R.); jasper.rymenants@kuleuven.be (J.R.); Lindsey.bervoets@kuleuven.be (L.B.); johan.neyts@kuleuven.be (J.N.)

2 State Key Laboratory of Drug Research, Shanghai Institute of Materia Medica, Chinese Academy of Sciences, 555 Zu Chong Zhi Road, Shanghai 201203, China; dwh1992@163.com (W.D.); jianl@simm.ac.cn (J.L.); sissilibingqian@gmail.com (B.L.)

3 College of Pharmacy, Nanjing University of Chinese Medicine, 138 Xianlin Avenue, Qixia District, Nanjing 210023, China

4 Laboratory for Molecular Biodiscovery, KU Leuven-Department of Pharmaceutical and Pharmacological Sciences, 3000 Leuven, Belgium; Peter.dewitte@kuleuven.be

* Correspondence: hliu@simm.ac.cn (H.L.); joana.rochapereira@kuleuven.be (J.R.-P.)

+ Equal contribution.

$\ddagger$ Co-senior authors.

check for updates

Citation: Van Dycke, J.; Dai, W.; Stylianidou, Z.; Li, J.; Cuvry, A.; Roux, E.; Li, B.; Rymenants, J.; Bervoets, L.; de Witte, P.; et al. A Novel Class of Norovirus Inhibitors Targeting the Viral Protease with Potent Antiviral Activity In Vitro and In Vivo. Viruses 2021, 13, 1852. https://doi.org/ $10.3390 / \mathrm{v} 13091852$

Academic Editor: Kim Y. Green

Received: 17 August 2021

Accepted: 11 September 2021

Published: 16 September 2021

Publisher's Note: MDPI stays neutral with regard to jurisdictional claims in published maps and institutional affiliations.

Copyright: (c) 2021 by the authors. Licensee MDPI, Basel, Switzerland. This article is an open access article distributed under the terms and conditions of the Creative Commons Attribution (CC BY) license (https:/ / creativecommons.org/licenses/by/ $4.0 /$ )

\begin{abstract}
Human noroviruses (HuNoVs) are the most common cause of viral gastroenteritis resulting annually in $\sim 219,000$ deaths and a societal cost of $\sim$ USD 60 billion, and no antivirals or vaccines are available. Here, we assess the anti-norovirus activity of new peptidomimetic aldehydes related to the protease inhibitor rupintrivir. The early hit compound 4 inhibited the replication of murine norovirus $(\mathrm{MNV})$ and the HuNoV GI.1 replicon in vitro $\left(\mathrm{EC}_{50} \sim 1 \mu \mathrm{M}\right)$ and swiftly cleared the HuNoV GI.1 replicon from the cells. Compound 4 still inhibits the proteolytic activity. We selected a resistant GI.1 replicon, with a mutation (I109V) in a highly conserved region of the viral protease, conferring a low yield of resistance against compound 4 and rupintrivir. After testing new derivatives, compound 10d was the most potent ( $\mathrm{EC}_{50}$ nanomolar range). Molecular docking indicated that the aldehyde group of compounds 4 and 10d bind with Cys139 in the HuNoV 3CL protease by a covalent linkage. Finally, compound 10d inhibited the replication of HuNoV GII.4 in infected zebrafish larvae, and PK studies in mice showed an adequate profile.
\end{abstract}

Keywords: Caliciviridae; antivirals; small molecule; danio rerio; infection

\section{Introduction}

Human norovirus ( $\mathrm{HuNoV}$ ) infections remain a major worldwide cause of gastroenteritis that affects people of all ages. $\mathrm{HuNoV}$ infections can be particularly severe in children, the elderly and immunocompromised. Annually, 700 million people will acquire a HuNoV infection and 219,000 people die. Moreover, there is a considerable yearly economic burden of USD 60 billion linked to HuNoV infections [1]. HuNoV is very contagious and causes large outbreaks, which have a significant health and economic impact, mostly in hospital wards and nursing homes. Chronic norovirus infections are problematic in immunodeficient patients, who may have diarrhea for months. There is still no approved antiviral available to treat and/or prevent a HuNoV infection, and the current treatment is merely supportive.

The norovirus nonstructural proteins constitute an attractive target for antiviral drug design. Here we focus on the norovirus protease, which displays a chymotrypsin-like fold 
with cysteine as the active-site nucleophile, similarly to the $3 \mathrm{C}$ protease of picornaviruses and the main protease of coronavirus [2,3]. The protease has the essential role of cleaving the polyprotein precursor into the individual mature nonstructural proteins [4], besides hampering the cellular immune response by cleavage of the mitochondrial antiviral signaling protein (MAVS) [5]. Protease-targeting antivirals have been developed to treat infections with human immunodeficiency virus (HIV), hepatitis $\mathrm{C}$ virus (HCV) or studied in clinical trials for human rhinovirus (HRV) [6]. Rupintrivir (AG 7088), a protease inhibitor that was originally designed to treat infections with HRVs, also showed antiviral activity against other viruses such as picorna-, corona- and caliciviruses but was not further developed [7-11].

\section{Materials and Methods}

\subsection{Viruses and Cells}

Murine norovirus (MNV, strain MNV 1.CW1) was propagated and RAW 264.7 cells were maintained as described earlier [12]. HGT cells bearing the HuNoV GI.1 replicon were provided by Ian Goodfellow (University of Cambridge) and were maintained as described earlier [13]. Cells were incubated at $37^{\circ} \mathrm{C}$ in a humidified atmosphere of $5 \% \mathrm{CO}_{2}$. To obtain the MNV virus stock, once full cytopathic effect (CPE) was observed, cells underwent two freeze-thaw cycles, and the virus was harvested from the supernatant after centrifugation $(10 \mathrm{~min}, 1000 \times g)$ and stored at $-80{ }^{\circ} \mathrm{C}$. The viral titer was determined by endpoint titration.

\subsection{Compounds}

Compounds were designed and synthesized as showed in Scheme 1 and in the Supplementary Materials and Methods. The materials and solvents were purchased from commercial sources and used without further purification. All products were characterized by the NMR and MS spectra; $1 \mathrm{H}$ and $13 \mathrm{C}$ NMR spectra were recorded on a $400 \mathrm{MHz}$, $500 \mathrm{MHz}$ or $600 \mathrm{MHz}$ instrument. Compounds were purified by chromatography with silica gel (300-400 mesh). Analytical thin-layer chromatography (TLC) was performed on HSGF 254 (0.15-0.2 mm thickness) sheets, and preparative thin-layer chromatography (PTLC) was performed on HSGF 254 (0.4-0.5 mm thickness) sheets. High-resolution mass spectra (HRMS) were measured on a Micromass Ultra Q-Tof spectrometer. For the antiviral experiments, compounds were dissolved in dimethyl sulfoxide (DMSO, VWR Chemicals, Leuven, Belgium).

The synthetic route of the compounds (4 and 10a-10d) is shown in Scheme 1, and the starting material for compound $\mathbf{1}$ was synthesized as described earlier [14]. The ester of compound $\mathbf{2}$ was condensed from compound $\mathbf{1}$ with 2-quinolinecarboxylic acid, and then the intermediate of compound 2 was subsequently reduced by $\mathrm{NaBH}_{4}$ to generate the corresponding alcohol (compound 3 ) which was oxidized into aldehydes (compound 4) with Dess-Martin periodinane (DMP). The other compounds (10a-10d) were also synthesized from the starting material of compound 1, and the intermediate (compound 5) was obtained from compound $\mathbf{1}$ and a $N$-(tert-Butoxycarbonyl)- $L$-valine. Subsequently, the intermediate (compound 6) was obtained by removing the $t$-butoxycarbonyl group of compound 5. Coupling compound $\mathbf{6}$ with the corresponding acid (compounds 7a-7d) yielded the esters intermediate (compounds $\mathbf{8 a}-\mathbf{8 d}$ ). Then the peptidomimetic aldehydes (compounds 10a-10d) were generated from compound $\mathbf{8 a}-\mathbf{8 d}$ via a two-step route. The synthesis procedure of the compounds can be found in the Supplementary Materials data. 


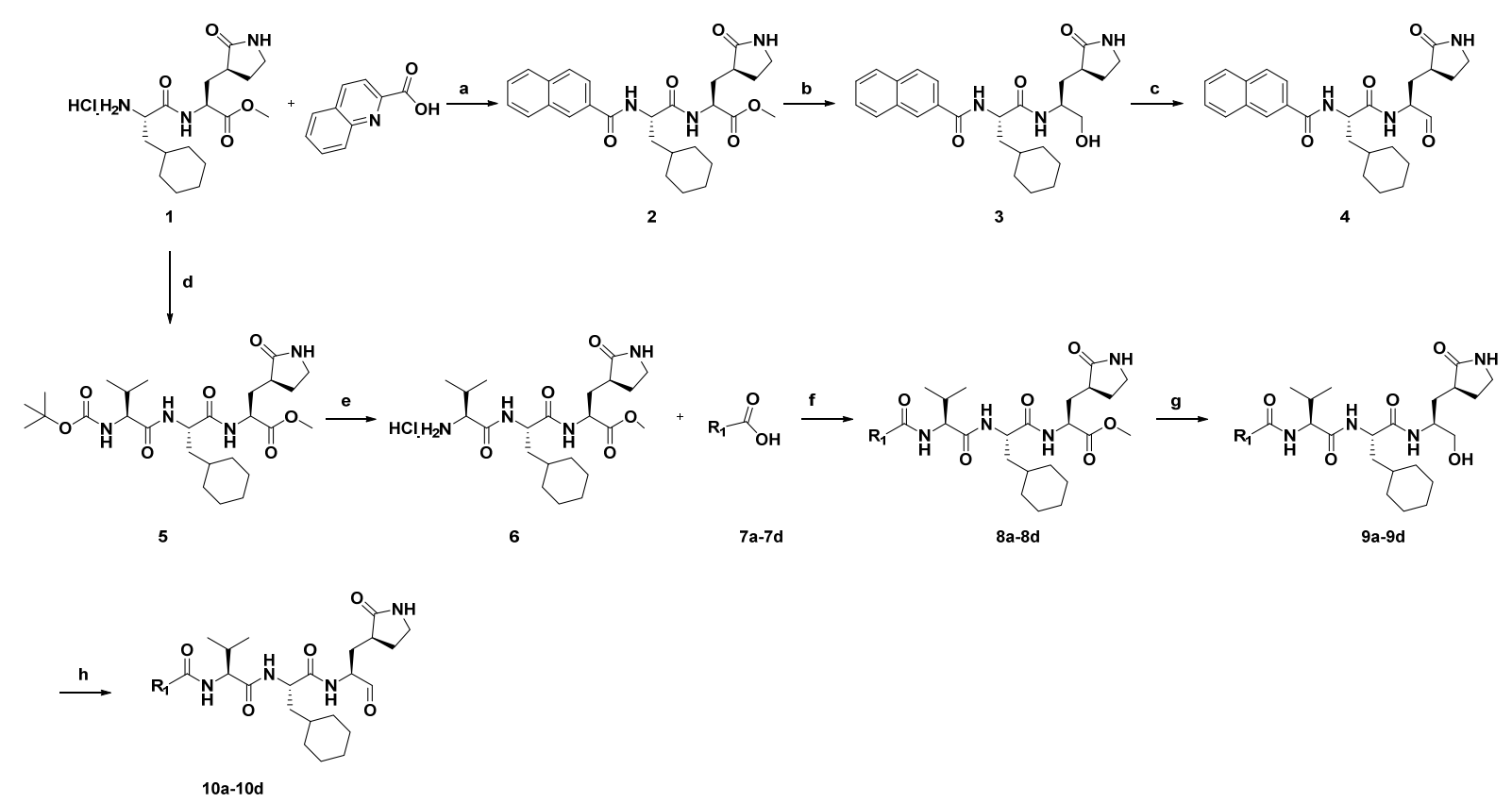

Scheme 1. Reagents and conditions. (a) HATU, DIPEA, $\mathrm{CH}_{2} \mathrm{Cl}_{2}, 2{ }^{\circ} \mathrm{C}, 12 \mathrm{~h}$; (b) $\mathrm{NaBH}_{4}, \mathrm{CH}_{3} \mathrm{OH}, \mathrm{CH}_{2} \mathrm{Cl}_{2}$; (c) Dess-Martin periodinane, $\mathrm{CH}_{2} \mathrm{Cl}_{2}$; (d) $\mathrm{N}$-(tert-Butoxycarbonyl)-L-valine, HATU, DIPEA, $\mathrm{CH}_{2} \mathrm{Cl}_{2}, 20^{\circ} \mathrm{C}, 12 \mathrm{~h}$; (e) $4 \mathrm{M} \mathrm{HCl}, 12 \mathrm{~h}$; (f) $\mathrm{HATU}$, DIPEA, $\mathrm{CH}_{2} \mathrm{Cl}_{2}, 20^{\circ} \mathrm{C}, 12 \mathrm{~h}$; (g) $\mathrm{NaBH}_{4}, \mathrm{CH}_{3} \mathrm{OH}, \mathrm{CH}_{2} \mathrm{Cl}_{2}$; (h) Dess-Martin periodinane, $\mathrm{CH}_{2} \mathrm{Cl}_{2}$.

\subsection{Antiviral and Cytotoxicity Assay}

Murine norovirus: The experiment was performed as described earlier [12]. In short, RAW 264.7 cells $\left(1 \times 10^{4}\right.$ cells/well) were infected with MNV.CW1 in the presence of a dilution series of compounds. Antiviral activity and cytotoxicity were determined using the MTS method. The $50 \%$ effective concentration $\left(\mathrm{EC}_{50}\right)$ was defined as the compound concentration that protected $50 \%$ of the cells from CPE. The $\%$ cell viability was calculated as $\left(\mathrm{OD}_{\text {treated }} / \mathrm{OD}_{\mathrm{CC}}\right) \times 10$, and the $50 \%$ cytotoxicity concentration $\left(\mathrm{CC}_{50}\right)$ was defined as the compound concentration that reduces the number of viable cells by $50 \%$.

HuNoV GI.1 replicon: The experiment was performed as described earlier with minor modifications [15]. In short, HGT cells $\left(3 \times 10^{2}\right.$ cells/well) were seeded into the wells of a 96-well plate without G418. After $24 \mathrm{~h}$ of incubation, serial dilutions of compounds were added. Cells were further incubated for $72 \mathrm{~h}$, and then cells were collected for RNA load quantification by RT-qPCR. To determine relative levels of Norwalk virus replicon RNA, $\beta$ actin was used as a normalizer and ratios were calculated as previously described [15]. The $\mathrm{EC}_{50}$ values were defined as the compound concentration that resulted in $50 \%$ reduction of the relative HuNoV GI.1 replicon RNA levels.

\subsection{Virus Yield Assay and RT-qPCR}

The supernatants of treated or untreated infected cells were harvested. The viral RNA was isolated from supernatant using the NucleoSpin RNA Virus Kit (MACHEREY-NAGEL, Düren, Germany), according to the manufacturer's protocol, and was quantified by a onestep RT-qPCR (Bio-Rad, Hercules, CA, USA). The primers, probe and cycling conditions were described earlier $[16,17]$.

\subsection{Generation of Drug-Resistant MNV Variants}

RAW 264.7 cells $\left(1 \times 10^{4}\right.$ cells / well) were seeded into the wells of 96-well plates and were infected with MNV.CW1 in the presence of a dilution series of compound 4 . When $\mathrm{CPE}$ was visible in the virus control (no compound), all the wells were scored for visible CPE. Virus was harvested from the wells in which CPE was observed under the highest compound pressure. The resistant virus was then diluted 1:5 and used to infect a new 
96-well plate under the same conditions to continue. After 30 passages ( 7 months), the viral RNA was isolated using the NucleoSpin RNA Virus Kit (MACHEREY-NAGEL Düren, Germany), after which a one-step RT-PCR (QIAGEN, Hilden, Germany) was performed and the sample sent for sequencing. Primers were 2950(+): $5^{\prime}$ accgccaggtcgactacg $3^{\prime}, 3981(-)$ : $5^{\prime}$ tcatacatgttgttggcgtg $3^{\prime}$. Sequences were analyzed and mutations were detected using the Geneious software version 2021.1.1 (Auckland, New Zealand). An untreated virus control was passaged in parallel and sequenced at the same time point to determine the background mutations occurring during serial passaging.

\subsection{HuNoV GI.1 Replicon Clearance Assay}

The experiment was performed as described earlier with minor modifications [11]. In short, HuNoV GI.1 replicons bearing HGT cells were seeded $\left(2.5 \times 10^{5}\right.$ cells $)$ in $25 \mathrm{~cm}^{2}$ T-flasks, with G418. The next day, cell culture medium was replaced for DMEM without G418 containing $10 \mu \mathrm{M}$ of compound 4 or no compound. When $90 \%$ confluent ( $\sim 3$ days later), cells were trypsinized: (i) $2.5 \times 10^{5}$ cells were seeded in a new $25 \mathrm{~cm}^{2}$ T-flask with the same concentration of compound 4 or no compound, (ii) $2.5 \times 10^{5}$ cells were seeded in a new $25 \mathrm{~cm}^{2}$ T-flask without compound but with $1.25 \mathrm{mg} / \mathrm{mL}$ compound 4 (rebound step), and (iii) $1.5 \times 10^{5}$ cells from each flask were collected for quantification of replicon $/ \beta$ actin RNA.

\subsection{Generation of Drug-Resistant HuNoV GI.1 Replicon Variants}

HuNoV GI.1 replicons bearing HGT cells were seeded $\left(2.5 \times 10^{5}\right.$ cells $)$ in $25 \mathrm{~cm}^{2}$ T-flasks, with G418 and $1 \mu \mathrm{M}$ of compound 4 (EC $\mathrm{EC}_{50}$ value). When $90 \%$ confluent (after $\sim 3$ days), cells were trypsinized: (i) $2.5 \times 10^{5}$ cells were seeded in a new $25 \mathrm{~cm}^{2}$ T-flask with the same concentration of compound 4, and (ii) $1.5 \times 10^{5}$ cells were collected and stored at $-80^{\circ} \mathrm{C}$ for isolation of viral RNA using the RNeasy Mini Kit (QIAGEN, Hilden, Germany). This was repeated once more before the concentration of compound 4 was increased 2-fold. A one-step RT-PCR (QIAGEN, Hilden, Germany) was performed with HuNoV GI.1 primers (FW: 5'-gccgtggtctgagtgatg- $3^{\prime}$, REV: $5^{\prime}$-ccaccatcaccacctgc $-3^{\prime}, 5^{\prime}$-caccatcaccacctgc- $3^{\prime}$ ) and sent for Sanger sequencing (Macrogen Inc). Sequences were analyzed and mutations were detected using the Geneious software version 2021.1.1 (Auckland, New Zealand). Untreated HGT cells were passaged in parallel and sequenced at the same time point to determine the background mutations occurring during serial passaging.

\subsection{Cell-Based Fluorescence Resonance Energy Transfer (FRET) Assay}

The assay was performed as described previously [18,19]. In short, HEK293T cells $\left(5 \times 10^{4}\right.$ cells /well) were seeded into black 96-well cell plates (Greiner, Vilvoorde, Belgium) in the presence of a dilution series of compounds, and cells were incubated at $37^{\circ} \mathrm{C}$ in a humidified atmosphere of $5 \% \mathrm{CO}_{2}$. After $4 \mathrm{~h}$, the cells were transfected with $0.1 \mu \mathrm{g}$ of protease plasmid and $0.1 \mu \mathrm{g}$ of the FRET plasmid (kindly provided by Prof. I. Goodfellow, University of Cambridge) with the TransIT ${ }^{\circledR}$ LT1 Transfection Reagent (Mirus Bio LCC, Madison, WI, USA) according to the manufacturer's protocol. The following day, the medium was removed and replaced with PBS (Gibco, Waltham, MA, USA). The fluorescent levels were analyzed on a Spark plate reader (Tecan, Männedorf, Switzerland), with excitation set at $434 \mathrm{~nm}$ and the reading emissions set at $477 \mathrm{~nm}$ cyan fluorescent protein (CFP) and $527 \mathrm{~nm}$ yellow fluorescent protein (YFP). The background fluorescence was measured and subtracted from wells transfected with an empty vector (pUC18). The 50\% inhibitory concentration $\left(\mathrm{IC}_{50}\right)$ values were calculated with nonlinear fitting in GraphPad version prism 7 (San Diego, CA, USA).

\subsection{Western Blot}

To detect the cleavage of the FRET sensor and the presence of the NS6 viral protein activity, HEK293T cells were harvested $24 \mathrm{~h}$ post transfection for western blot analysis. Transfected cells were lysed in RIPA buffer (Thermo Scientific, Waltham, MA, USA) in 
the presence of a protease inhibitor (Halt Protease Inhibitor Cocktail kit), centrifuged at $9000 \mathrm{~g}$ for $5 \mathrm{~min}$ at $4{ }^{\circ} \mathrm{C}$ and sonicated for 4 times $5 \mathrm{~min}$ at $4{ }^{\circ} \mathrm{C}$. Protein concentration of the lysates was determined using the BCA protein assay kit (Thermo Scientific, Waltham, MA, USA). Three $\mu \mathrm{g}$ of cell lysates were analyzed by SDS-PAGE and Western blotting. Proteins were separated by SDS-PAGE (Criterion XT gel, 10\% Bis-Tris, Bio-Rad, Hercules, CA, USA) and transferred onto a PVDF membrane (Trans-Blot Turbo, Bio-Rad, Hercules, CA, USA). After blocking with 1\% PBS T milk for $1 \mathrm{~h}$, the membranes were incubated overnight with an anti-RFP antibody (ChromoTek, 6G6), anti-GFP antibody (ChromoTek, PABG1, Planegg, Germany) or anti-GAPDH antibody (Sigma, SAB2701826, Darmstadt, Germany) at a 1:1000 dilution. The next day, the membranes were washed extensively and incubated with species-specific horseradish peroxidase (HRP) conjugated secondary antibodies (Dako). Proteins were detected using chemiluminescence according to the manufacturer's instructions (Thermo Scientific, SuperSignal West Femto Maximum Sensitivity Substrate, Waltham, MA, USA) using the ChemiDoc MP Imaging System.

\subsection{Site-Directed Mutagenesis}

The desired mutations were introduced into the protease cDNA clones using the QuikChange II XL mutagenesis kit (Agilent, Santa Clara, CA, USA) according to the manufacturer's instructions. The presence of the desired mutation in the produced construct was confirmed by PCR, and Sanger sequencing was performed (Macrogen Inc., Seoul, Korea).

\subsection{Antiviral Treatment of HuNoV-Infected Zebrafish Larvae via Injections in the Pericardial Cavity}

Zebrafish larvae were anesthetized and positioned as previously [20,21], in short: zebrafish larvae of three days post fertilization (dpf) were anesthetized and transferred to an agarose mold to position them on their dorsal side with the yolk facing upward. In every experiment, the injection needle was calibrated to ensure the precision of the injection volume. Microinjection was performed using an M3301R Manual Micromanipulator (WPI, Friedberg, Germany) and a FemtoJet 4i pressure microinjector (Eppendorf, Hamburg, Germany). Compound-treated zebrafish larvae received a $1 \mathrm{~nL}$ injection of compound in pericardial cavity, while negative control zebrafish were injected with $1 \mathrm{~nL}$ of phosphatebuffered saline (PBS). Zebrafish larvae were injected in the yolk with $3 \mathrm{~nL}$ of virus or with $3 \mathrm{~nL}$ of PBS (negative control).

After injection, zebrafish larvae were transferred to 6-well plates with Danieau's solution and further maintained in an incubator with a $14 / 10 \mathrm{~h} \mathrm{light} /$ dark cycle at $32{ }^{\circ} \mathrm{C}$. Every day post injection, the general condition of the zebrafish larvae (e.g., posture, swimming behavior or signs of edema) was observed in order to record clinical signs of virus infection, and 10 zebrafish larvae were collected and stored at $80{ }^{\circ} \mathrm{C}$.

\subsection{Tissue Homogenization, RNA Extraction and RT-qPCR-qPCR for Detection of Human Norovirus}

Zebrafish larvae were homogenized (Precellys 24, Bertin Technologies, Montigny-leBretonneux, France), the homogenates were cleared by centrifugation ( $5 \mathrm{~min}, 9000 \times g)$, and RNA was extracted using the RNeasy Mini Kit (QIAGEN, Hilden, Germany), according to the manufacturer's protocol. RNA levels were quantified with a one-step RT-qPCR (iTaq Universal Probes One-Step Kit, Bio-Rad, Hercules, CA, USA) as previously described $[20,21]$.

\subsection{Pharmacokinetic Studies in Mice}

Male CD-1 mice ( 3 per group, weight 18-28 g) were treated with a solution of compound 4 or $10 \mathrm{~d}(\mathrm{DMSO} / \mathrm{EtOH} / \mathrm{PEG} 300 / \mathrm{NaCl}(5 / 5 / 40 / 50, v / v / v / v))$ at doses of $20 \mathrm{mg} / \mathrm{kg}$ via intraperitoneal administration, $5 \mathrm{mg} / \mathrm{kg}$ via subcutaneous administration or $5 \mathrm{mg} / \mathrm{kg}$ via intraperitoneal administration. Blood samples were collected at $0.05,0.25,0.75,2,4,8$ and $24 \mathrm{~h}$ after administration. Serum samples were obtained through common procedures, and the concentrations of compound in the supernatant were analyzed by LC-MS/MS. All 
procedures relating to animal handling, care and treatment were performed according to the guidelines approved by the Institute Animal Care and Use Committee at Shanghai Institute of Materia Medica.

\section{Results}

In the search for a norovirus-protease-targeting antiviral, we screened $~ 300$ peptidomimetic aldehydes. Compound 4 (Figure 1) inhibited mouse norovirus (MNV)-induced $\mathrm{CPE}$ and viral RNA with an $\mathrm{EC}_{50}$ value of $0.7 \pm 0.2 \mu \mathrm{M}$ and $1.7 \pm 0.6 \mu \mathrm{M}$, respectively. A $\mathrm{CC}_{50}$ value of $25.3 \pm 6.1 \mu \mathrm{M}$ was determined, resulting in a selectivity index (SI) of 35.6. In addition, compound 4 also inhibited the HuNoV GI.1 replicon $\left(\mathrm{EC}_{50}: 1.2 \pm 0.6 \mu \mathrm{M}\right)$ and showed no adverse effects on the host cells up to the hi0 ghest tested concentration of $100 \mu \mathrm{M}$.
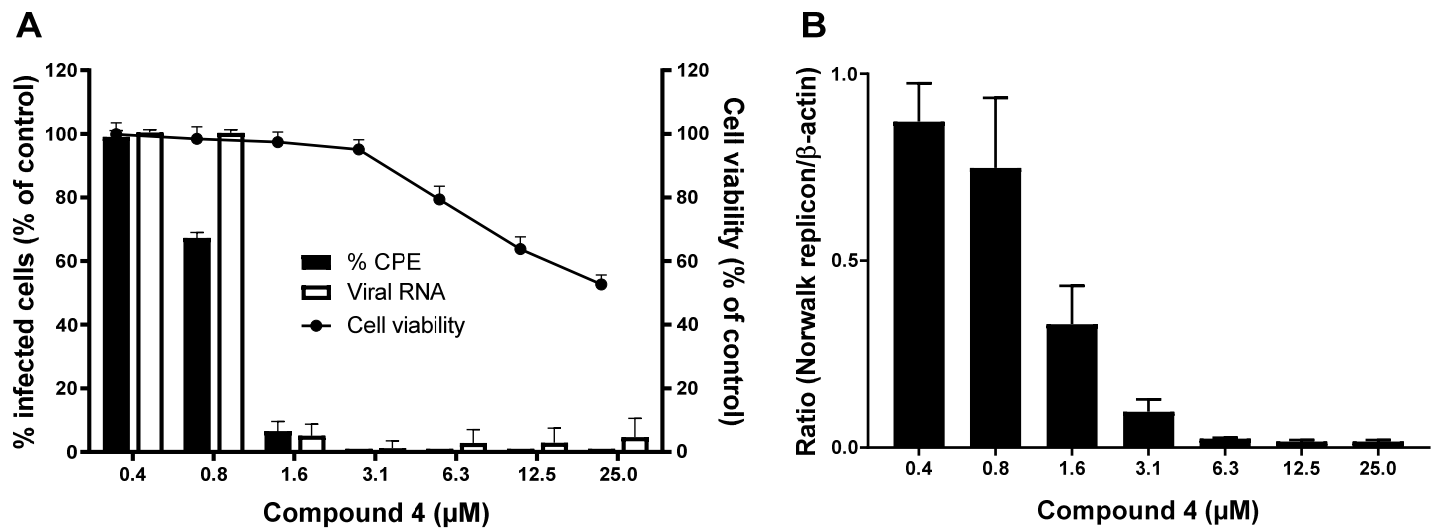

Figure 1. The antiviral effect of compound 4 against MNV and the HuNoV GI.1 replicon. (A) The antiviral activity of compound 4 against MNV was quantified by (i) virus-induced CPE reduction and (ii) reduction in viral RNA levels. Cellular toxicity was assessed in parallel. $n=3-4( \pm$ SEM). (B) The antiviral activity of compound 4 against the HuNoV GI.1 replicon. Intracellular RNA loads are represented by relative genome quantification of the HuNoV GI.1 replicon versus $\beta$-actin. $n=5( \pm$ SEM).

Next, HuNoV GI.1 replicon bearing HGT cells were treated with $10 \mu \mathrm{M}\left(\sim 10 \mathrm{x} \mathrm{EC}_{50}\right)$ in multiple passages [15]. This resulted in a $2 \log _{10}$ reduction in HuNoV GI.1 RNA (Figure 2A) after two passages and in a $3 \log _{10}$ reduction after three passages. Compound 4 could clear cells from the HuNoV GI.1 replicon completely, as after two consecutive treatments with $10 \mu \mathrm{M}$, the HGT cells had lost the ability to replicate with G418 (Figure 2B).

To evaluate the dynamics of emerging resistance against compound 4, cells containing MNV and HuNoV GI.1 replicon were cultured under sub-optimal concentrations. After 25 passages (6 months), a weak compound $4^{\text {res }}$ MNV variant developed. The MNV compound $4^{\text {res }}$ variant had a minor shift in $\mathrm{EC}_{50}$ of 4.5 -fold. However, no mutations in the protease gene were found that could be linked to the resistant phenotype. Similarly, HGT cells carrying the HuNoV GI.1 replicon were cultured under sub-optimal concentrations. After three months, a compound $4^{\text {res }}$ HuNoV GI.1 replicon variant was selected, with a shift in $\mathrm{EC}_{50}$ of 13.8-fold (Table 1). Similarly, we selected for a rupintrivir-resistant $\mathrm{HuNoV}$ GI.1 replicon variant, with the compound pressure up to $14 \mu \mathrm{M}$, and a shift in $\mathrm{EC}_{50}$ of 15-fold was obtained (Table 1). 
A

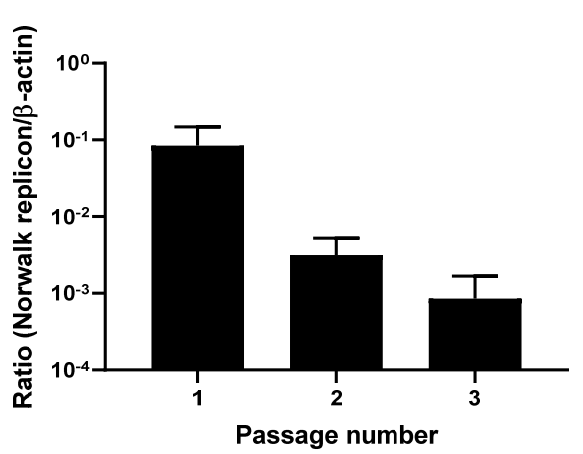

B

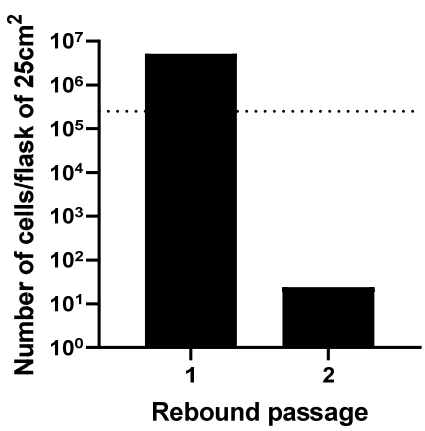

Figure 2. Clearance of the HuNoV GI.1 replicon from HGT cells by compound 4. (A) Clearance phase: cells were treated for three consecutive passages with compound $4(10 \mu \mathrm{M})$ without G418. (B) Rebound phase: cells from the clearance phase were placed under selective pressure with G418, without compound 4 . The dotted line represents the minimum number of HGT cells required for the next passage.

Table 1. Selection of compound 4 and rupintrivir-resistant HuNoV GI.1 replicon variants.

\begin{tabular}{|c|c|c|}
\hline \multicolumn{3}{|c|}{ Compound 4} \\
\hline Selection Pressure & $\mathrm{EC}_{50}(\mu \mathrm{M})$ & Fold Change in $\mathrm{EC}_{50}$ \\
\hline DMSO control & $0.8 \pm 0.3$ & - \\
\hline $6 \mu \mathrm{M}$ of compound 4 & 3.8 & 4.5 \\
\hline $10 \mu \mathrm{M}$ of compound 4 & 4.3 & 5.2 \\
\hline $16 \mu \mathrm{M}$ of compound 4 & $11.5 \pm 0.9$ & 13.8 \\
\hline \multicolumn{3}{|c|}{ Rupintrivir } \\
\hline Selection Pressure & $\mathrm{EC}_{50}(\mu \mathrm{M})$ & Fold Change in $\mathrm{EC}_{50}$ \\
\hline DMSO control & $1.0 \pm 0.1$ & - \\
\hline $10 \mu \mathrm{M}$ of rupintrivir & $9.4 \pm 0.5$ & 9.3 \\
\hline $14 \mu \mathrm{M}$ of rupintrivir & $15 \pm 3$ & 15.2 \\
\hline
\end{tabular}

When compound $4^{\text {res }}$ HGT cells were treated with rupintrivir, a shift in $\mathrm{EC}_{50}$ of 10.8-fold was observed $\left(\mathrm{EC}_{50} 10.9 \pm 4.17 \mu \mathrm{M}\right)$. While treatment of rupintrivir ${ }^{\text {res }} \mathrm{HGT}$ cells with compound 4 resulted in a smaller shift of 6.8 -fold $\left(\mathrm{EC}_{50} 5.67 \pm 0.73 \mu \mathrm{M}\right)$. Sequence analysis of the compound $4^{\text {res }} \mathrm{HuNoV}$ GI.1 replicon variant revealed one mutation in the protease (I109V); the selected rupintrivir ${ }^{\text {res }}$ variant carried another mutation (A105V). These amino acids are highly conserved within the Caliciviridae (Figure S1). The I109V mutation was previously associated with in vitro resistance to rupintrivir; a double A105V/I109V mutation was also reported [22].

To confirm that compound 4 acts by inhibiting the proteolytic activity of the HuNoV protease and the relevance of the identified resistant mutations, we studied the activity of the compound in a FRET-based protease assay [18]. When the protease is absent, blocked or inactive (H30A), a high YFP signal but a low CFP signal is detected (Figure 3A). In contrast, the wild-type (WT) or mutated proteases (A105V, I109V, A105V/I109V) show strong cleavage of the FRET linker, resulting in a low YFP signal but a high CFP signal. We confirmed the presence of the protease and that the loss of the FRET signal was linked to a successful cleavage (Figure 3B). A dose-dependent effect was noted when compound 4 or rupintrivir was added to cells transfected with one of the norovirus proteases (Figure 3C). Rupintrivir inhibited the protease with $\mathrm{IC}_{50}$ values of $3 \mu \mathrm{M}(\mathrm{CI}: 2.5-3.5 \mu \mathrm{M})$ for the GI.1 protease, $12.2 \mu \mathrm{M}(\mathrm{CI}: 9.1-16.3 \mu \mathrm{M})$ for the GII protease and $4.6 \mu \mathrm{M}(\mathrm{CI}$ : 3.8-5.5 $\mu \mathrm{M})$ for the $\mathrm{GV}$ protease; these values are comparable with a previous study [22]. Compound 4 was less potent, with $\mathrm{IC}_{50}$ values of $34 \mu \mathrm{M}(\mathrm{CI}$ : 28.6-40.31 $\mu \mathrm{M})$ for the GI.1 protease, $40.6 \mu \mathrm{M}$ (CI: 34.9-47.2 $\mu \mathrm{M})$ for the GII protease and 32.5 $\mu \mathrm{M}(\mathrm{CI}$ : 28.5-37.0 $\mu \mathrm{M})$ for the GV protease. 
A
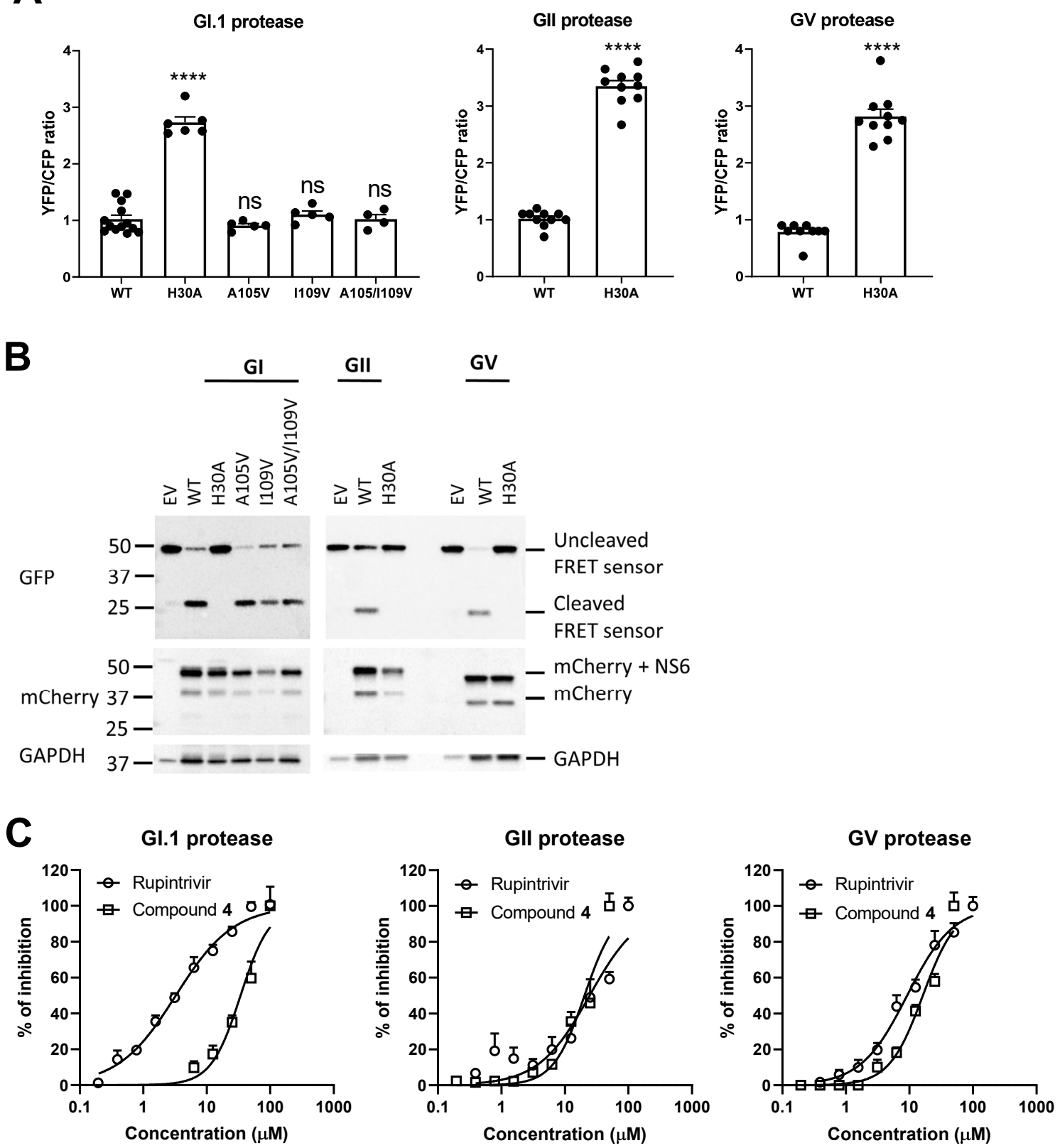

Figure 3. Compound 4 and rupintrivir block the norovirus protease. (A) The FRET signal was lost upon co-transfection with the wild-type (WT) or a mutated protease (A105V, I109V, A105V/I109V). The signal remained upon co-transfection with the inactive (H30A) protease. (B) Western blot of HEK293T cells co-transfected with the GI, GII or GV WT or mutant proteases along with the FRET construct. Cleavage was observed in the WT and mutant proteases in all genogroups. EV: empty vector. (C) Dose-response curves of compound 4 and rupintrivir on the WT proteases. Mean values \pm SEM are presented, Mann-Whitney test ${ }^{* * *} p<0.0001$, ns: not significant.

We confirmed that the mutant GI.1 proteases still had a strong cleavage activity, comparable to that of the WT protease (Figure 3A,B). In the FRET assay, the A105V mutation and the A105V/I109V mutation in a GI.1 protease resulted in a significant shift in $\mathrm{IC}_{50}$ value for rupintrivir but not for compound 4 . The single I109V mutation did not result in a significant reduction of the GI.1 protease sensitivity to rupintrivir or compound 4 (Figure 4). 

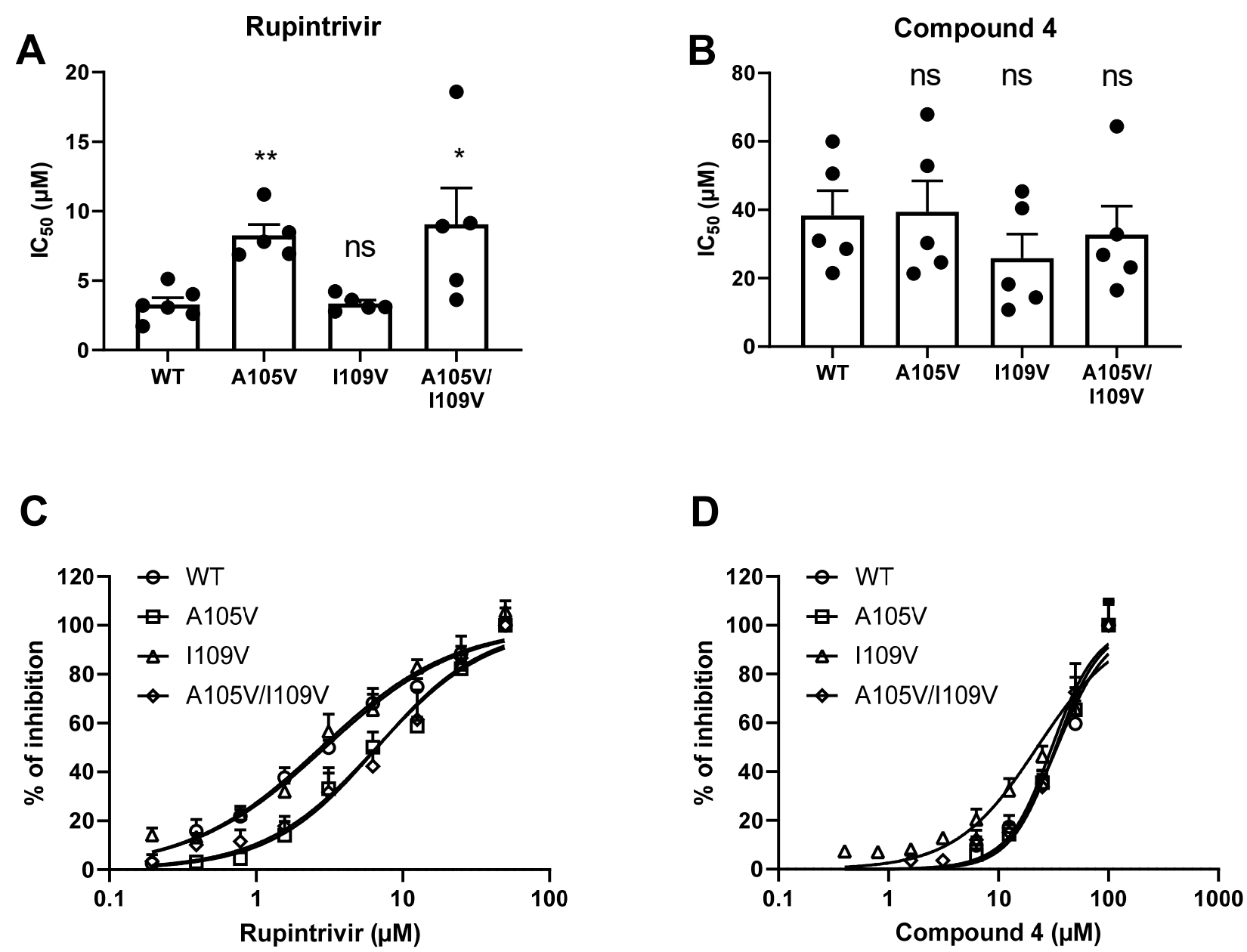

Figure 4. The susceptibility of mutated GI.1 proteases to rupintrivir and compound 4. $\mathrm{IC}_{50}$ values of rupintrivir (A) and compound 4 (B) on the WT or mutant GI proteases. Dose-response inhibition curves of rupintrivir (C) and compound 4 (D) on the WT or mutant GI proteases. Mean values \pm SEM are presented, Mann-Whitney test ${ }^{* *} p<0.01,{ }^{*} p<0.05$, ns: not significant.

Molecular-docking studies indicate that compound 4 can occupy the 3CL protease (GI.1 and GII.4 norovirus) active site (Figure S2). The aldehyde group of compound 4 can form a C-S covalent bond with 3CL protease, and the (S)-lactam ring occupies the S1 subsite of the 3CLprotease. In GI.1 norovirus 3CL ${ }^{\text {pro- }}$ compound 4, the S2 subsite can be occupied by the cyclohexyl, while the cyclohexyl cannot fit the S2 subsite of GII.4 norovirus 3CL ${ }^{\text {pro }}$.

As the initial hit, compound 4, did not show a superior antiviral effect to rupintrivir, novel derivatives were synthetized to increase the potency of this class (Table 2).

Of the active analogues, compound $10 \mathrm{~d}$ (Figure 5) showed to have a very potent inhibitory effect against both GI and GV noroviruses. It inhibited MNV-induced CPE with an $\mathrm{EC}_{50}$ value of $0.037 \pm 0.016 \mu \mathrm{M}$ and viral RNA synthesis with an $\mathrm{EC}_{50}$ value of $0.03 \pm 0.01 \mu \mathrm{M}$, and a $\mathrm{CC}_{50}$ value of $48 \pm 3 \mu \mathrm{M}$ was determined, resulting in a selectivity index (SI) of $>1000$. In addition, compound $10 \mathrm{~d}$ showed strong antiviral activity against the HuNoV GI.1 replicon with an $\mathrm{EC}_{50}$ value of $0.012 \pm 0.010 \mu \mathrm{M}$ and without adverse effects on the host cells up to the highest tested concentration of $100 \mu \mathrm{M}$. 
Table 2. Structures of tetrapeptide inhibitors with $\mathrm{R}_{1}$ modifications and their antiviral activities against MNV and the HuNoV replicon.<smiles>[R]C(=O)NC(C(=O)N[C@@H](CC1CCCCC1)C(=O)N[C@@H](C=O)C[C@@H]1CCNC1=O)C(C)C</smiles>

\begin{tabular}{cccc}
\hline No. & MNV-EC $_{50}(\mu \mathrm{M})$ & HuNoV-EC $_{50}(\mu \mathrm{M})$ \\
\hline $\mathbf{1 0 a}$ & $3.8 \pm 0.97$ & $0.24 \pm 0.11$ \\
$\mathbf{1 0 b}$ & $0.23 \pm 0.11$ & $0.016 \pm 0.009$ \\
$\mathbf{1 0}$ & $0.094 \pm 0.014$ & $0.016 \pm 0.006$ \\
\hline
\end{tabular}

\section{A}

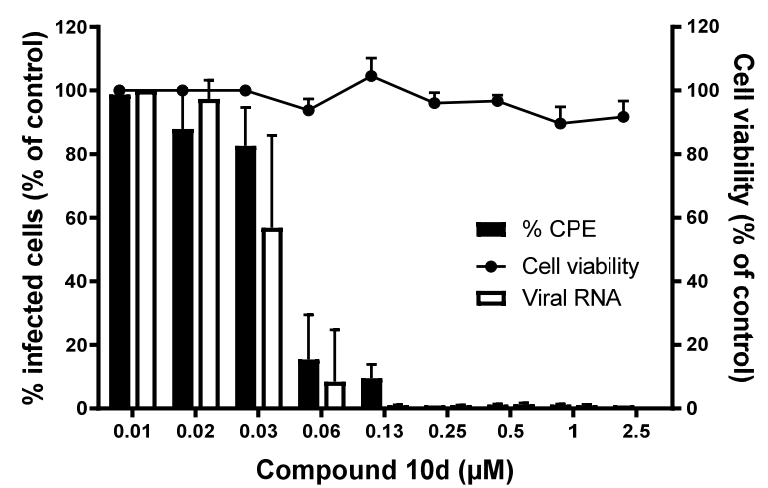

B

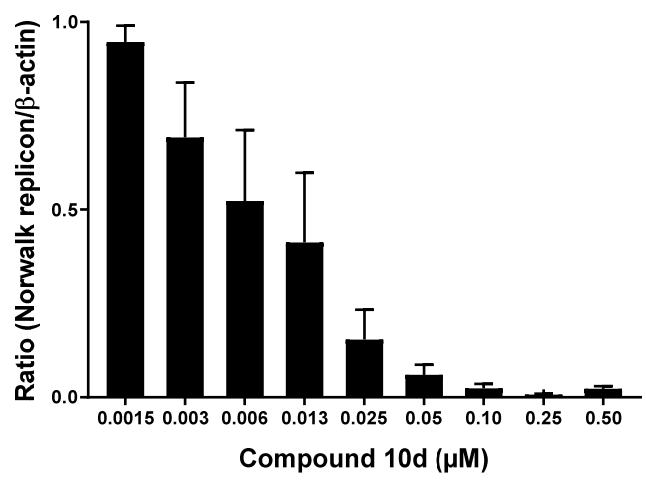

Figure 5. The antiviral effect of compound 10d against MNV and the HuNoV GI.1 replicon. (A) The antiviral activity of compound 10d against MNV was quantified by (i) virus-induced CPE reduction and (ii) reduction in viral RNA levels. Cellular toxicity was assessed in parallel. $n=3-4$ ( \pm SEM). (B) The antiviral activity of compound 10d against the HuNoV GI.1 replicon. Intracellular RNA loads are represented by relative genome quantification of the HuNoV GI.1 replicon versus $\beta$-actin. $n=3( \pm \mathrm{SEM})$.

Also in the FRET protease assay, compound 10d was much more potent in blocking the different proteases than compound 4 and rupintrivir (Figure 6A). Treatment with compound 10d resulted in $\mathrm{IC}_{50}$ values of $0.09 \mu \mathrm{M}(\mathrm{CI}: 0.08-0.11 \mu \mathrm{M})$ for the GI.1 protease, $0.12 \mu \mathrm{M}(\mathrm{CI}: 0.09-0.14 \mu \mathrm{M})$ for the GII protease and $0.49 \mu \mathrm{M}(\mathrm{CI}: 0.42-0.56 \mu \mathrm{M})$ for the GV protease. Likewise, we investigated if the mutations (A105V, I109V, A105V/I109V) affected the susceptibility of the HuNoV GI.1 protease to compound 10d. The GI.1 protease was less susceptible to the compound in the presence of each of the mutations (Figure 6B). The I109V mutation yielded a greater shift in $\mathrm{IC}_{50}$ value $(2.5$-fold), while the $\mathrm{A} 105 \mathrm{~V}$ and A105V/I109V resulted in a 1.6-fold change (Figure 6C). 
A

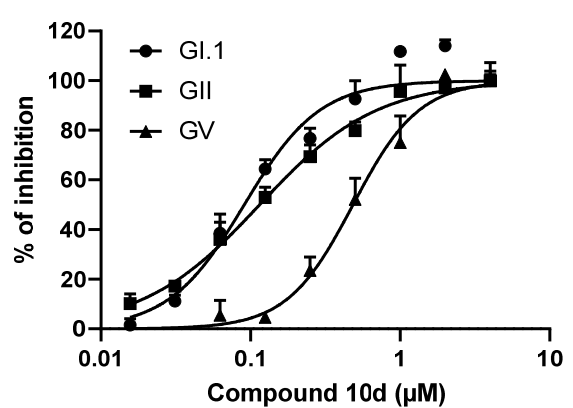

C

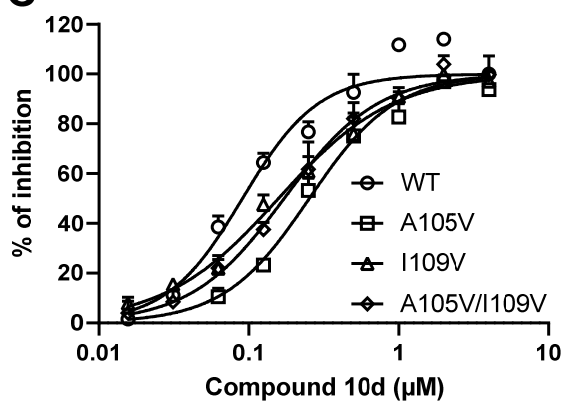

B

Compound 10d

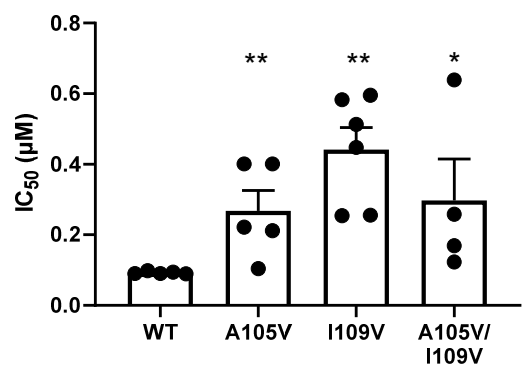

Figure 6. The susceptibility of mutated GI.1 proteases to compound 10d. (A) Dose-response inhibition curves showing the effect of compound $10 \mathrm{~d}$ on the WT proteases. (B) $\mathrm{IC}_{50}$ values of compound 10d on the WT or mutant GI.1 proteases. (C) Dose-response inhibition curves showing the effect of compound 10d on the WT or mutant GI proteases. Mean values \pm SEM are presented, Mann-Whitney test, ${ }^{* *} p<0.01,{ }^{*} p<0.05$.

Molecular docking indicates that compound 10d occupies the 3CL protease (GI.1 norovirus) and GII.4 norovirus active site well (Figure 7). The interacted model of GI.1 norovirus $3 \mathrm{CL}^{\text {pro }}$ compound $10 \mathrm{~d}$ shows that the aldehyde group of compound $10 \mathrm{~d}$ plays a crucial role in maintaining the antiviral activities. The carbon atom of the aldehyde group can bind with Cys139, and the oxygen atom forms a hydrogen bond with Ile135, Gly137 and Asp138. The (S)-lactam ring occupies the S1 subsite, and the lactam group interacts with Thr134; furthermore, the cyclohexyl fits well into the S2 subsite. In addition, the amide bonds of compound 10d can form hydrogen bonds with Gly137. The interacted model (Figure 7C,D) also shows that the compound 10d can occupy the GII.4 norovirus 3CL pro well as the (S)-lactam ring fits the S1 subsite and the cyclohexyl can occupy the S2 subsite.

The aldehyde group of compound 10d also plays an important role against the GII.4 norovirus 3CL pro. The carbon atom of the aldehyde group can bind with Cys139, and the oxygen atom forms a hydrogen bond with Arg112 and Pro136. In addition, the (S)-lactam ring interacts with Thr134 in S1 subsite. The amine bonds of compound 10d can also interact with His30 and Arg112. This explains why compound 10d shows potent antiviral activity against GI.1 and GII.4 norovirus.

Finally, we evaluated whether these compounds have an in vivo antiviral effect against $\mathrm{HuNoV}$ in zebrafish larvae [20]. We injected $5.6 \mathrm{ng}$ of compound $\mathbf{1 0 d}$ in the pericardial cavity immediately before virus inoculation; adding the compound to the swimming water was not possible given the low water solubility. No toxic effects (abnormal body shape, impaired circulation/arrhythmia, impaired motility, edema) were observed with any of the concentrations tested. A single injection with $5.6 \mathrm{ng}$ of compound 10 resulted in a $0.6 \log _{10}$ reduction in HuNoV GII.4 viral RNA titers $(p=0.0062)$ at day 2 post infection, i.e., the peak of replication (Figure 8). 

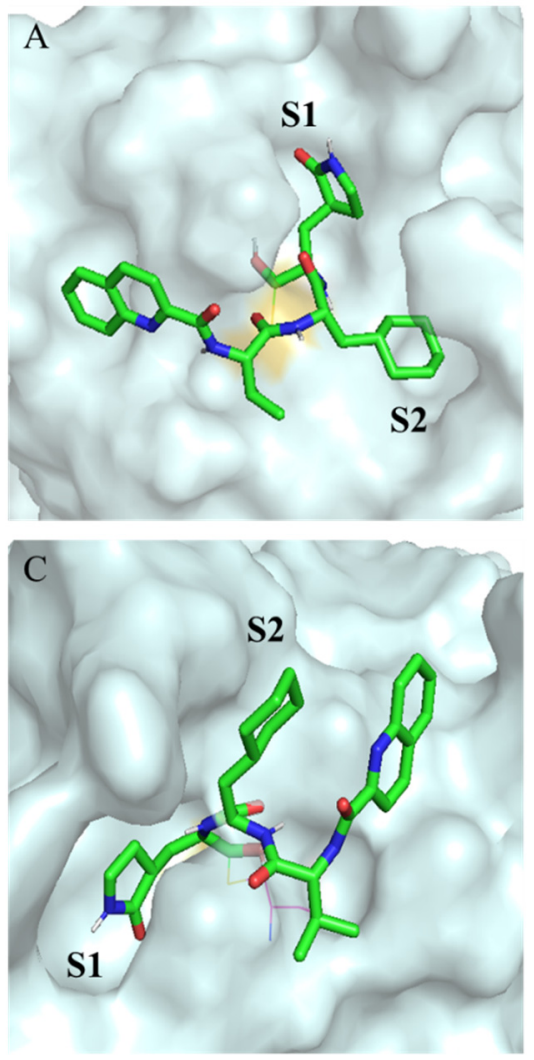

B

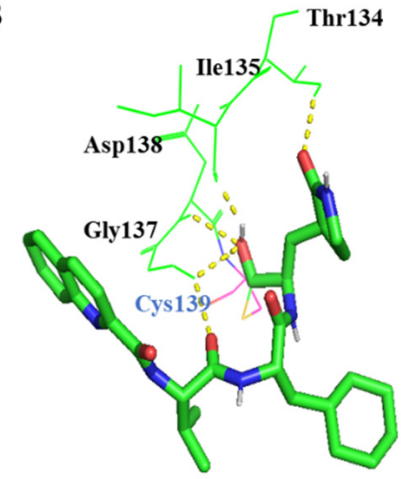

$\mathrm{D}$

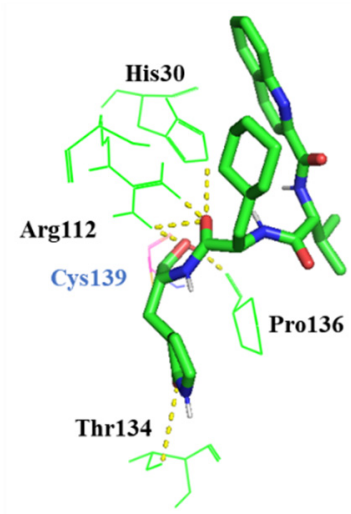

Figure 7. Molecular docking of compound 10d in the GI.1 and GII.4 norovirus 3CL protease. (A) The binding mode of $10 \mathrm{~d}$ at the substrate-binding site of the GI.1 norovirus 3CL ${ }^{\text {pro }}$ (PDB code: 3UR9). The GI.1 norovirus 3CL ${ }^{\text {ro }}$ was shown as molecular surface and $10 \mathrm{~d}$ was shown by green sticks. (B) Interactions of $10 \mathrm{~d}$ with the surrounding residues. Residues are shown as light green lines, and $\mathrm{H}$ bonds are represented by yellow dashed lines. (C) The binding mode of $\mathbf{1 0 d}$ at the substrate-binding site of the GII.4 norovirus 3CL pro (PDB code: 6NIR). (D) Interactions of 10d with the surrounding residues. The Schrödinger program (Maestro covalent docking) was used for calculations and PyMOL program for visualizations.

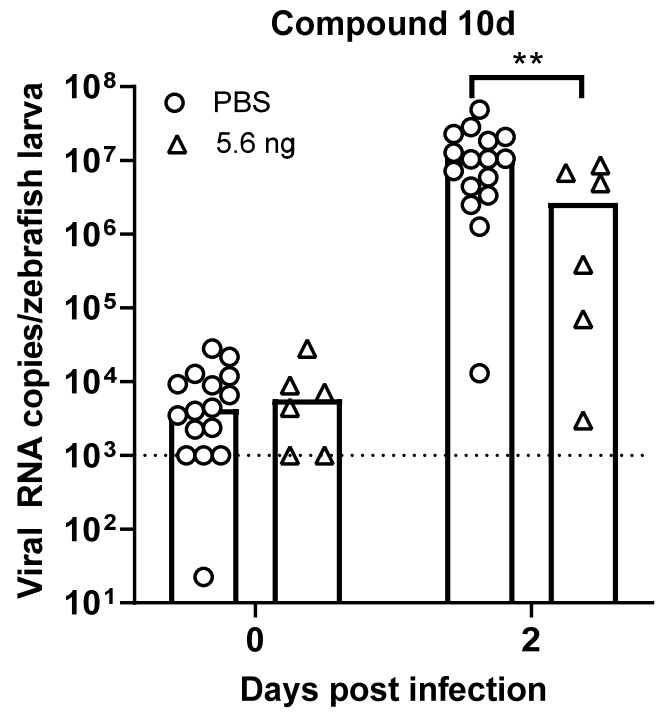

Figure 8. Compound 10d reduces HuNoV GII.4 replication in zebrafish larvae. Single treatment of zebrafish infected with HuNoV GII.P4-GII.4 with compound 10d ( $n=6-11)$. The dotted line represents the limit of detection (LOD), mean values \pm SEM, Mann-Whitney test, ${ }^{* *} p<0.01$. 
The pharmacokinetic properties of compounds 4 and $10 \mathrm{~d}$ were evaluated in CD-1 mice (Table 3). Compound 4 displayed a moderate half-life $\left(\mathrm{T}_{1 / 2}\right)$, high maximal concentration, high area under the curve (AUC) value and good bioavailability. Compound 10d displayed a long $T_{1 / 2}$, high $C_{\max }$ value, AUC value and good bioavailability.

Table 3. Preliminary pharmacokinetic (PK) evaluation of compounds 4 and 10d.

\begin{tabular}{|c|c|c|c|c|c|c|c|c|c|c|}
\hline Compd. & Route & $\begin{array}{l}T_{1 / 2} \\
(h)\end{array}$ & $\begin{array}{c}\mathrm{T}_{\max } \\
\text { (h) }\end{array}$ & $\underset{(\mathrm{ng} / \mathrm{mL})}{\mathrm{C}_{\max }}$ & $\begin{array}{c}\mathrm{AUC}_{\text {last }} \\
(\mathrm{h} \cdot \mathrm{ng} / \mathrm{mL})\end{array}$ & $\begin{array}{c}\text { AUC }_{\text {INF_obs }} \\
(\mathrm{h} \cdot \mathrm{ng} / \mathrm{mL})\end{array}$ & $\begin{array}{c}\mathrm{CL}_{\text {_obs }} \\
(\mathrm{mL} / \mathrm{min} / \mathrm{kg})\end{array}$ & $\begin{array}{l}\operatorname{MRT}_{\text {INF_obs }} \\
\text { (h) }\end{array}$ & $\begin{array}{l}\text { Vss obs } \\
\text { (mL/kg) }\end{array}$ & $\begin{array}{c}F \\
(\%)\end{array}$ \\
\hline \multirow{3}{*}{4} & $\begin{array}{c}\text { i.p. } \\
(20 \mathrm{mg} / \mathrm{kg})\end{array}$ & $5.11 \pm 1.07$ & 0.250 & $14,492 \pm 2881$ & $14,883 \pm 1775$ & $14,954 \pm 1789$ & - & $1.40 \pm 0.06$ & & 72.1 \\
\hline & $\begin{array}{c}\text { s.c. } \\
(5 \mathrm{mg} / \mathrm{kg})\end{array}$ & $5.63 \pm 0.40$ & $0.58 \pm 0.29$ & $2196 \pm 894$ & $4057 \pm 1142$ & $4114 \pm 1138$ & - & $2.95 \pm 0.53$ & & 78.6 \\
\hline & $\begin{array}{c}\text { i.v. } \\
(5 \mathrm{mg} / \mathrm{kg})\end{array}$ & $5.50 \pm 0.85$ & - & - & $5161 \pm 1316$ & $5193 \pm 1302$ & $16.8 \pm 4.4$ & $1.44 \pm 0.30$ & $1498 \pm 714$ & \\
\hline \multirow{3}{*}{$10 \mathrm{~d}$} & $\begin{array}{c}\text { i.p. } \\
(20 \mathrm{mg} / \mathrm{kg})\end{array}$ & $4.26 \pm 0.24$ & 0.25 & $12,657 \pm 5906$ & $10,788 \pm 3929$ & $10,815 \pm 3933$ & - & $1.34 \pm 0.29$ & - & 150 \\
\hline & $\begin{array}{c}\text { s.c. } \\
(5 \mathrm{mg} / \mathrm{kg})\end{array}$ & $6.02 \pm 0.92$ & $0.42 \pm 0.29$ & $1568 \pm 582$ & $1843 \pm 717$ & $1857 \pm 718$ & - & $1.70 \pm 0.16$ & & 102 \\
\hline & $\begin{array}{l}\text { i.v. } \\
(5 \mathrm{mg} / \mathrm{kg})\end{array}$ & $5.64 \pm 1.63$ & - & - & $1799 \pm 63$ & $1812 \pm 67$ & $46.0 \pm 1.7$ & $1.40 \pm 0.23$ & $3867 \pm 758$ & \\
\hline
\end{tabular}

$\mathrm{T}_{1 / 2}$ : half-life, i.p.: intraperitoneal administration, s.c.: subcutaneous administration, $\mathrm{C}_{\text {max }}$ : maximal concentration, $\mathrm{AUC}$ : area under the curve, INF_obs: from time 0 extrapolated to infinite time, $\mathrm{CL}_{\mathrm{obs}}$ : clearance, $\mathrm{MRT}$ : mean residence time, Vss: steady-state volume of distribution, F: bioavailability.

\section{Discussion}

In the search for an antiviral against HuNoV infections, we evaluated a compound library of $\sim 300$ compounds structurally related to the protease inhibitor rupintrivir for their potential anti-norovirus activity.

The early hit compound, compound $\mathbf{4}$, showed to have an equipotent effect against GI and GV noroviruses. The activity of compound 4 against the HuNoV GI.1 replicon is comparable to rupintrivir; moreover, compound 4 could clear cells from the HuNoV GI.1 replicon thus confirming it has a strong antiviral effect. In addition, compound 4 performs better against $\mathrm{MNV}$ than rupintrivir $\left(\mathrm{EC}_{50}: 13 \pm 2 \mu \mathrm{M}\right)$ [11]. We thus considered this as a promising class of compounds, given that protease inhibitors described thus far tend to be less potent against non-GI noroviruses when compared to GI [23].

The first attempt to obtain better insight into the mechanism of action was made by selecting for drug-resistant variants. We succeeded in selecting for a compound $4^{\text {res }} \mathrm{HuNoV}$ GI.1 replicon variant. Upon sequencing, a single mutation was detected in the protease (I109V), which had been previously associated with a weak resistance to rupintrivir [22] Interestingly, when we selected for a rupintrivir ${ }^{\text {res }} \mathrm{HuNoV}$ GI.1 replicon variant, another mutation was identified (A105V). Since we selected for rupintrivir-resistant clones that contain solely the A105V mutation, our data suggest that this could be more than a compensatory mutation, as was suggested by Kitano et al. The double mutation (A105V / A109V) that was reported before [22] was not found it in this study, perhaps due to differences in the protocol. Overall, the close position of the identified mutations and the (at least partial) cross-resistance observed lead us to hypothesize that compound 4 most likely interacts with the same residues of the HuNoV GI.1 protease and acts by (nearly) the same molecular mechanism as rupintrivir.

In the FRET assay, compound 4 was active against all proteases but 3 - to 10-fold less potent than rupintrivir. This could be explained by the fact that this FRET assay might not take place in the same subcellular localization in which proteolytic cleavage takes place after a natural infection. Upon introduction of the mutations in the GI protease, we confirmed that the A105V and A105V/I109V but not the I109V mutation contributed to the reduced susceptibility to rupintrivir but not to compound 4 . This could be due to the rather low potency of the molecule in this assay, which does not help to make evident small shifts in $\mathrm{IC}_{50}$ values. In addition, the proteases containing the double mutant were not more resistant to rupintrivir than the single mutants. Taken together, one can conclude that additional mutations are necessary to result in full resistance and thus that the barrier to 
resistance of antivirals targeting the norovirus protease is high. This is an important plus point in favor of the development of such a class of antivirals against norovirus.

Aiming to improve the activity, additional derivatives were synthetized and tested. Of those, compound 10d was about 100-fold more potent with $\mathrm{EC}_{50}$ values in the doubledigit nanomolar range. This was further confirmed in the FRET assay, with a 300-fold improvement against the GI and GII proteases. By using the mutated GI proteases, we found reduced susceptibility to compound $10 \mathrm{~d}$, although this was a very low-grade resistance. This compound class shows to be less potent against GII than GI noroviruses, as other protease-targeting compounds [23]. Nevertheless, the best compound still has submicromolar potency against the GII protease $\left(\mathrm{IC}_{50}\right.$ of $\left.0.12 \mu \mathrm{M}\right)$. It would be of interest to study the antiviral effect of this compound in human gut enteroids infected with GII $\mathrm{HuNoV}$ [24].

Finally, we evaluated the in vivo antiviral effect of compound $10 \mathrm{~d}$ against $\mathrm{HuNoV}$ GII.4 [20]. Upon a single-treatment of compound 10d immediately before virus inoculation, a $0.6 \log _{10}$ reduction in viral RNA was observed at the peak of replication. This was achieved by a dose of around $22.5 \mathrm{ng} / \mathrm{mg}$ which is still a relatively low dose compared to rodents. Moreover, compounds 4 and $10 \mathrm{~d}$ have good PK properties in mice that warrant further development.

As the proteases of corona-, picorna- and caliciviruses have well-known structural similarities, this class of compounds was also tested against SARS-CoV-2 [14]. Hence, the further development of these compounds to treat COVID-19 patients could not only be an important breakthrough for the control of the current pandemic but also lead to the first approved and urgently needed antiviral treatment for norovirus infections. Of note is that protease inhibitors are known to have adverse effects $[25,26]$, thus this aspect should be carefully assessed during their preclinical development. However, the current inhibitors targeting HIV and HCV protease are safe, and this class of compounds has thus far shown no reasons for concern regarding acute toxicity [14].

\section{Conclusions}

In conclusion, we described here a novel class of peptidomimetic aldehydes with potent antiviral activity against noroviruses in vitro and in a small animal model. Our findings highlight once more that the $\mathrm{HuNoV}$ protease is an attractive target for the development of norovirus antivirals with a high barrier to resistance. For the first time, a class of protease inhibitors was shown to be active against HuNoV GII.4 in a small animal model. Overall, we believe that these compounds should be further developed for the treatment of HuNoV-induced disease (as well as against corona- and enterovirus infections).

Supplementary Materials: The following are available online at https:/ /www.mdpi.com/article/10 $.3390 / \mathrm{v} 13091852 / \mathrm{s} 1$, Methods on synthesis procedure and compound data, Figure S1: Amino acid sequence alignment of norovirus proteases, Figure S2: Molecular docking was performed to study the potential interactions between compound $\mathbf{4}$ with the GI.1 and GII.4 norovirus 3CL pro.

Author Contributions: Writing, figures and revision, J.V.D., J.R.-P., H.L., W.D.; design and synthesis of compounds, W.D., J.L., H.L.; molecular docking, B.L.; experimental work, J.V.D., A.C., W.D., E.R., Z.S., J.R., L.B.; supervision and funding acquisition, P.d.W., H.L., J.R.-P., J.N. All authors have read and agreed to the published version of the manuscript.

Funding: J.V.D. was an S.B. doctoral fellow of the Scientific Fund for Research of Flanders (FWO). A.C. is a doctoral fellow supported by an internal KU Leuven grant. We gratefully acknowledge financial support from the National Natural Science Foundation of China (grants 21632008 and 81620108027).

Institutional Review Board Statement: All zebrafish experiments were approved and performed according to the rule of KU Leuven (P086/2017) in compliance with the regulations of the European Union (EU) concerning the welfare of laboratory animals as declared in Directive 2020/569/EU. All procedures relating to mice handling, care and treatment were performed according to the guidelines approved by the Institute Animal Care and Use Committee at Shanghai Institute of Materia Medica.

Informed Consent Statement: Not applicable. 
Data Availability Statement: The data presented in this study are all presented in the manuscript.

Acknowledgments: We thankIan Goodfellow (University of Cambridge) for providing the HGT cells bearing the HuNoV GI.1 replicon and FRET plasmid. We thank the KU Leuven aquatic facility for breeding the zebrafish larvae.

Conflicts of Interest: The authors declare no conflict of interest.

\section{References}

1. Bartsch, S.M.; Lopman, B.A.; Ozawa, S.; Hall, A.J.; Lee, B.Y. Global Economic Burden of Norovirus Gastroenteritis. PLoS ONE 2016, 11, e0151219. [CrossRef]

2. Zeitler, C.E.; Estes, M.K.; Venkataram Prasad, B.V. X-ray crystallographic structure of the Norwalk virus protease at 1.5-A resolution. J. Virol. 2006, 80, 5050-5058. [CrossRef]

3. Zhang, L.; Lin, D.; Kusov, Y.; Nian, Y.; Ma, Q.; Wang, J.; von Brunn, A.; Leyssen, P.; Lanko, K.; Neyts, J.; et al. $\alpha-$ Ketoamides as Broad-Spectrum Inhibitors of Coronavirus and Enterovirus Replication: Structure-Based Design, Synthesis, and Activity Assessment. J. Med. Chem. 2020, 63, 4562-4578. [CrossRef]

4. Blakeney, S.J.; Cahill, A.; Reilly, P.A. Processing of Norwalk virus nonstructural proteins by a 3C-like cysteine proteinase. Virology 2003, 308, 216-224. [CrossRef]

5. Hyde, J.L.; Mackenzie, J.M. Subcellular localization of the MNV-1 ORF1 proteins and their potential roles in the formation of the MNV-1 replication complex. Virology 2010, 406, 138-148. [CrossRef] [PubMed]

6. Chang, K.O.; Kim, Y.; Lovell, S.; Rathnayake, A.D.; Groutas, W.C. Antiviral Drug Discovery: Norovirus Proteases and Development of Inhibitors. Viruses 2019, 11, 197. [CrossRef] [PubMed]

7. Binford, S.L.; Maldonado, F.; Brothers, M.A.; Weady, P.T.; Zalman, L.S.; Meador, J.W., 3rd; Matthews, D.A.; Patick, A.K. Conservation of amino acids in human rhinovirus $3 \mathrm{C}$ protease correlates with broad-spectrum antiviral activity of rupintrivir, a novel human rhinovirus 3C protease inhibitor. Antimicrob. Agents Chemother. 2005, 49, 619-626. [CrossRef] [PubMed]

8. Patick, A.K.; Binford, S.L.; Brothers, M.A.; Jackson, R.L.; Ford, C.E.; Diem, M.D.; Maldonado, F.; Dragovich, P.S.; Zhou, R.; Prins, T.J.; et al. In vitro antiviral activity of AG7088, a potent inhibitor of human rhinovirus 3C protease. Antimicrob. Agents Chemother. 1999, 43, 2444-2450. [CrossRef]

9. Patick, A.K. Rhinovirus chemotherapy. Antiviral. Res. 2006, 71, 391-396. [CrossRef]

10. Kim, Y.; Lovell, S.; Tiew, K.C.; Mandadapu, S.R.; Alliston, K.R.; Battaile, K.P.; Groutas, W.C.; Chang, K.O. Broad-spectrum antivirals against $3 C$ or 3C-like proteases of picornaviruses, noroviruses, and coronaviruses. J. Virol. 2012, 86, 11754-11762. [CrossRef] [PubMed]

11. Rocha-Pereira, J.; Nascimento, M.S.; Ma, Q.; Hilgenfeld, R.; Neyts, J.; Jochmans, D. The enterovirus protease inhibitor rupintrivir exerts cross-genotypic anti-norovirus activity and clears cells from the norovirus replicon. Antimicrob. Agents Chemother. 2014, 58, 4675-4681. [CrossRef] [PubMed]

12. Rocha-Pereira, J.; Jochmans, D.; Dallmeier, K.; Leyssen, P.; Nascimento, M.S.; Neyts, J. Favipiravir (T-705) inhibits in vitro norovirus replication. Biochem. Biophys. Res. Commun. 2012, 424, 777-780. [CrossRef] [PubMed]

13. Arthur, S.E.; Sorgeloos, F.; Hosmillo, M.; Goodfellow, I. Epigenetic suppression of interferon lambda receptor expression leads to enhanced HuNoV replication in vitro. bioRxiv 2019, 523282. [CrossRef]

14. Dai, W.; Zhang, B.; Jiang, X.-M.; Su, H.; Li, J.; Zhao, Y.; Xie, X.; Jin, Z.; Peng, J.; Liu, F.; et al. Structure-based design of antiviral drug candidates targeting the SARS-CoV-2 main protease. Science 2020, 368, 1331-1335. [CrossRef] [PubMed]

15. Rocha-Pereira, J.; Jochmans, D.; Debing, Y.; Verbeken, E.; Nascimento, M.S.; Neyts, J. The viral polymerase inhibitor 2'-Cmethylcytidine inhibits Norwalk virus replication and protects against norovirus-induced diarrhea and mortality in a mouse model. J. Virol. 2013, 87, 11798-11805. [CrossRef]

16. Schul, W.; Liu, W.; Xu, H.Y.; Flamand, M.; Vasudevan, S.G. A dengue fever viremia model in mice shows reduction in viral replication and suppression of the inflammatory response after treatment with antiviral drugs. J. Infect. Dis. 2007, 195, 665-674. [CrossRef]

17. Van Dycke, J.; Arnoldi, F.; Papa, G.; Vandepoele, J.; Burrone, O.R.; Mastrangelo, E.; Tarantino, D.; Heylen, E.; Neyts, J.; RochaPereira, J. A Single Nucleoside Viral Polymerase Inhibitor Against Norovirus, Rotavirus, and Sapovirus-Induced Diarrhea. J. Infect. Dis. 2018, 218, 1753-1758. [CrossRef]

18. Emmott, E.; Sweeney, T.R.; Goodfellow, I. A Cell-based Fluorescence Resonance Energy Transfer (FRET) Sensor Reveals Interand Intragenogroup Variations in Norovirus Protease Activity and Polyprotein Cleavage. J. Biol. Chem. 2015, 290, 27841-27853. [CrossRef]

19. Felber, L.M.; Cloutier, S.M.; Kündig, C.; Kishi, T.; Brossard, V.; Jichlinski, P.; Leisinger, H.J.; Deperthes, D. Evaluation of the CFP-substrate-YFP system for protease studies: Advantages and limitations. BioTechniques 2004, 36, 878-885. [CrossRef]

20. Van Dycke, J.; Ny, A.; Conceição-Neto, N.; Maes, J.; Hosmillo, M.; Cuvry, A.; Goodfellow, I.; Nogueira, T.C.; Verbeken, E.; Matthijnssens, J.; et al. A robust human norovirus replication model in zebrafish larvae. PLoS Pathog. 2019, 15, e1008009. [CrossRef] 
21. Van Dycke, J.; Cuvry, A.; Knickmann, J.; Ny, A.; Rakers, S.; Taube, S.; de Witte, P.; Neyts, J.; Rocha-Pereira, J. Infection of zebrafish larvae with human norovirus and evaluation of the in vivo efficacy of small-molecule inhibitors. Nat. Protoc. 2021, 16, 1830-1849. [CrossRef] [PubMed]

22. Kitano, M.; Hosmillo, M.; Emmott, E.; Lu, J.; Goodfellow, I. Selection and Characterization of Rupintrivir-Resistant Norwalk Virus Replicon Cells In Vitro. Antimicrob. Agents Chemother. 2018, 62, e00201-18. [CrossRef] [PubMed]

23. Viskovska, M.A.; Zhao, B.; Shanker, S.; Choi, J.M.; Deng, L.; Song, Y.; Palzkill, T.; Hu, L.; Estes, M.K.; Venkataram Prasad, B.V. GII.4 Norovirus Protease Shows pH-Sensitive Proteolysis with a Unique Arg-His Pairing in the Catalytic Site. J. Virol. 2019, 93. [CrossRef]

24. Ettayebi, K.; Crawford, S.E.; Murakami, K.; Broughman, J.R.; Karandikar, U.; Tenge, V.R.; Neill, F.H.; Blutt, S.E.; Zeng, X.-L.; Qu, L.; et al. Replication of human noroviruses in stem cell-derived human enteroids. Science 2016, 353, 1387-1393. [CrossRef] [PubMed]

25. Chow, W.A.; Jiang, C.; Guan, M. Anti-HIV drugs for cancer therapeutics: Back to the future? Lancet Oncol. 2009, 10, 61-71. [CrossRef]

26. Koltai, T. Nelfinavir and other protease inhibitors in cancer: Mechanisms involved in anticancer activity. F1000Research $2015,4,9$. [CrossRef] 